\title{
An E-Portfolio as an Assessment Strategy in an Open Distance Learning Context
}

\author{
Matlala V. Makokotlela, University of South Africa, Pretoria, South Africa
}

https://orcid.org/0000-0003-0297-7408

\begin{abstract}
There has been a growing interest in using an e-portfolio as an alternative method of assessment in an open distance eLearning environment. The use of an e-portfolio as another method of assessment in Environmental Education (EE) has not been sufficiently researched. The purpose of this study was to explore how the use of an e-Portfolio as an alternative method of assessment enhances preservice teachers' technological pedagogy in an environmental education module. Qualitative data was collected using interviews and document analysis. The study employed interpretive paradigm, connectivism theory, and purposive sampling. A qualitative approach was employed to analyse and identify emerging themes from the data. The qualitative findings are that the e-portfolio was significant in assessing sustainable education, enhanced the pre-service teachers' digital pedagogy. Challenges included a lack of computer skills, connectivity, support during compilation of e-portfolio, and sufficient activities to promote teachers' digital pedagogy.
\end{abstract}

\section{KEYWORDS}

Collaboration, Community of Practice, Connectivism, Digital Pedagogy, Environmental Education, Higher Education, Pre-Service Teachers, Technological Competencies

\section{INTRODUCTION}

E-portfolios as an alternative assessment tool to enhance pre-service teachers' digital pedagogy has recently become more common in the Open Distance eLearning (ODeL) context. Van Wyk (2017) states that, over the last decade, teachers have become more exposed to technologies that impact on classroom environments, teaching methods, strategies and techniques, and that this technological change requires teachers to have an in-depth understanding of digital pedagogy or technical pedagogical content knowledge (TPCK). This is because recent developments in higher education have shown the need for integrating technology in teaching and learning (Okaz, 2014; Van Wyk, 2017). The use of an e-portfolio as a way of assessment in ODeL is a response to recent developments in higher education where assessment is integral to teaching and learning. This suggests that the need to integrate technology in teaching and learning brought about a need to integrate technology in assessment in ODeL. It would not make sense if the recent developments or transformation of integrating technology in teaching and learning in ODeL omitted assessment because it is inseparable from teaching and learning. The use of an e-portfolio as a method of 
assessment in EE has been under-researched. The purpose of this study was to explore how the use of an e-portfolio as an alternative method of assessment enhances pre-service teachers' technological pedagogy in an environmental education module.

\section{BACKGROUND}

Global literature reveals that e-portfolios are defined differently based on the various academic environments and their use, but that they convey common features (Bhattacharya \& Hartnett, 2007; Hallam \& Creagh, 2010; Henrich, 2008; Morze \& Buinytska, 2015). E-portfolios are defined differently because they are used in different contexts for different purposes (Dunbar-Hall, Rowley, Bennett, Blom $\&$ Hitchcock, 2016; Heinrich, 2008). An e-portfolio was introduced as an alternative way of assessment because higher education is transforming from a paper-based teaching and learning approach to an e-learning approach as mentioned earlier. This change calls for a re-think of pre-service teachers' pedagogy from traditional to digital. According to Boulton (2014), an e-portfolio is a multi-modal evidence-based assessment method currently introduced in most teacher education programmes at higher education institutions locally and globally. Van Wyk (2017) refers to an e-portfolio as an alternative assessment strategy for student-teachers' self-directed learning empowerment that afforded them an opportunity to use various types of information technology (IT) tools such as podcasts, blogs, PowerPoint presentations and e-discussion forums. Transformation in higher education in terms of the use of technologies in teaching and learning as well as assessment is a global trend, meaning that there should be a re-think in terms of preparing pre-service teachers' pedagogy. This is the reason for exploring how the use of an e-portfolio as an alternative method of summative assessment enhances pre-service teachers' technological pedagogy in an environmental education (EE) module.

Smolyaninova and Shilina (2011) argue that teacher education programmes do not satisfactorily prepare pre-service teachers in terms of technological competency. Technological competency in this context means competency in digital pedagogy. An e-portfolio should, as Van Wyk (2017) mentions, provide pre-service teachers with in-depth understanding of digital pedagogy or TPCK.

An honours-level EE module, namely, whole school development through environmental education (WSDEE) at an African university was mostly taken up by pre-service teachers who had not been applying educational technologies in their teaching and learning or assessment activities. This was the case because, in the past, distance education depended on the postal delivery of hardcopy educational materials to the students and their postal delivery of assignments back to the university. However, the distance learning environment has undergone transformation in the digital era, with an increasing emphasis on the use of IT. Consequently, an e-portfolio was introduced to provide an alternative summative assessment method for the WSDEE module with the intention of making the module more suited to the online ODeL environment in enhancing the pre-service students' TPCK.

With regard to this study, an e-portfolio should provide pre-service teachers with technological competencies that enable them to cope with the current demands of teaching and learning in the digital classroom. The lens through which this phenomenon was explored is explained in the following section.

\section{THEORETICAL BASE}

Connectivism was used as a lens to explore the introduction of an e-portfolio as an alternative summative assessment tool in ODeL. However, this is not its only purpose: an e-portfolio should enable students to connect with each other as they interact and collaborate using technology to share ideas and evidence. This viewpoint is supported by Siemen's (2004) principles of connectivism that consider learning and knowledge as being situated within a diversity of views of learning and as a process of linking particular nodes of knowledge or data sources, which Downes (2007, p. 23) calls a "network of contacts". Thus, an e-portfolio connects both the lecturer with the pre-service teachers 
and the pre-service teachers with one another as a community with the intention of enhancing preservice teachers' technological pedagogy.

Siemens (2005) points out that, in connectivism, learning begins when knowledge is triggered, and a student connects to and contributes data within a learning community. The author views a community as a group of people with common areas of interest that allow for interaction, sharing, dialoguing and thinking together. An e-portfolio affords the students an opportunity to form such a community of practice.

For this study, connectivism is used in conjunction with the Mmogo (meaning togetherness) theory referring to a community of interaction (Roos, 2012). According to Kop and Hill (2008), connectivism's cannot be regarded as a stand-alone learning theory. Theories need to complement one another (Ally, 2004) and the author deemed it necessary to use these two theories together.

An e-portfolio connects the lecturer and the pre-service teachers through summative assessment and enhance their digital pedagogy. Furthermore, it facilitates the formation of a community of practice in which students communicate, collaborate, interact, share ideas, evidence, and dialogue through technology when compiling their e-portfolios (Roos, 2012; Siemens, 2005). The study's guiding research questions are listed below followed by literature review.

RQ1: What is the significance of an e-portfolio as an alternative way of assessment in EE?

RQ2: How does the use of an e-portfolio as another method of assessment enhance pre-service teachers' digital pedagogy?

RQ3: How does the use of an e-portfolio as an alternative assessment tool develop collaborative skills?

\section{LITERATURE REVIEW}

Van Wyk (2017) maintains that teachers are obliged to have a clear understanding of digital pedagogy due to technological changes in the teaching and learning environment. Maor (2017) states that e-portfolios are used to create digital pedagogies to enhance the students' learning experience. It is crucial that an e-portfolio is developed by pre-service teachers to enhance their technological pedagogy since the current teaching and learning environment requires such pedagogy. This suggests that digital pedagogy includes digital assessment in the ODeL context; hence, the introduction of an e-portfolio as an alternative method of summative assessment. Smolyaninova and Shilina (2011) highlight that in the field of professional pedagogy, an e-portfolio is used to assess personal achievements, which is relevant to pre-service teachers.

An e-portfolio provides an opportunity to introduce alternative assessment in courses like EE which do not focus on information technology aspects, per se. Smolyaninova and Shilina (2011) further indicate that the use of technology provides a systematic approach to assessment for Bachelor/ Master's programme students specialising in education, and the use of an e-portfolio as an alternative assessment tool improves the technological competence of pre-service teachers.

Examples of where e-portfolios have been introduced in South African universities are provided below:

- In the Faculty of Education and the Faculty of Economic and Management Sciences at the University of Stellenbosch (Strydom \& Barnard, 2017). At the University of Stellenbosch, students are exposed to blogs which they have to share through Google Hangouts and to upload some artefacts (Strydom \& Barnard, 2017);

- In the Economics subject within the Department of Curriculum and Instructional Studies at the University of South Africa (Van Wyk, 2017). An e-portfolio is used as a strategy for assessment at the University of South Africa to explore student teachers' opinions on the helpfulness of an e-portfolio as an empowering tool which can enhance pre-service teachers' digital pedagogy (Van Wyk, 2017). 
Van Wyk (2017) has this to say:

e-portfolios must not be seen as 'nice-to-have' idea but be used as an integrated technology and pedagogy approach as vital components for the successful implementation of the e-portfolio as an alternative assessment strategy in preservice teachers' empowerment. (p 288)

This means an e-portfolio should empower pre-service teachers with technological competencies and improve their technological pedagogy which is required in teaching and learning in the digital era.

The three research questions are addressed in the sections below.

\section{The Significance of an E-Portfolio as an Alternative Method of Assessment}

The use of an e-portfolio is important because it provides an opportunity to introduce an alternative assessment tool that is appropriate for the digital era. Rather than having to write a traditional examination, student-teachers are assessed on their ability to use digital resources to present evidence of their learning. E-portfolios may also be used to evaluate the success of the courses or modules in expanding the use of IT in the field of professional pedagogy (Bates, 2010; Smolyaninova \& Shilina, 2011).

The assessment requirements should start by exploring the types of the interactions that would contribute to the completion of the activity (Dillenbourg, 1999) because activities for e-assessment are aimed at improving learning (Mimirinis, 2018); in this case, both conceptual learning of EE topics and development of technological knowledge.

\section{The Use of an E-Portfolio as a Method of Assessment to Enhance Pre-Service Teachers' Digital Pedagogy}

An e-portfolio may be used as a self-directed learning tool that should enhance pre-service teachers' technological pedagogy (Van Wyk, 2017). An e-portfolio should empower pre-service teachers with technological competence to meet the requirements of the current classroom context. It is, therefore, imperative to explore how the use of an e-portfolio for summative assessment improves pre-service students' technological pedagogy.

According to Strydom and Barnard (2017), an e-portfolio may be used in any discipline to showcase skills developed. For this study, an e-portfolio was selected as an example of an alternative summative assessment tool for the WSDEE module being offered by an African University to explore how e-portfolios enable students to provide various types of evidence to demonstrate their learning on sustainability (an EE topic) (Habron, 2015). This study explored how e-portfolios enhance preservice students' technological pedagogy because the WSDEE module is taught in the digital space, thus bringing assessment in the EE field in line with the digital era to which pre-service teachers are exposed, especially in the classroom context. Following the above discussion, it can be said that the use of e-portfolios for summative assessment is beneficial to the students.

It has been highlighted by Van Wyk (2017) that teachers must have a clear understanding of digital pedagogy due to technological changes in the teaching and learning environment. Changes in approaches to assessment cannot, therefore, be ignored because it is an integral part of teaching and learning.

\section{The Development of Collaboration Through an E-Portfolio}

Collaboration is viewed as one of the essential skills for living in the $21^{\text {st }}$ century (Binkley et al., 2012; New Zealand Ministry of Education, 2007). Therefore, collaboration is important for EE students to share environmental experiences and knowledge (Odeke, 2012). In this case, collaboration is crucial because students must interact and share ideas and evidence during the compilation of their 
e-portfolios. This means the compilation of an e-portfolio relates to theories such as Mmogo (Roos, 2012; Siemens, 2005).

An e-portfolio is an empowering tool that enhances pre-service student-teachers' self-directed learning in a module where they develop collaborative skills when compiling and sharing evidence (Van Wyk, 2017). Bhattacharya and Hartnett (2007) view collaborative activities as an essential part of an e-portfolio in which the traditional paper-based portfolio is replaced by a digital format to address the requirements of the digital teaching context. This suggests that an e-portfolio can enhance pre-service teachers' technological pedagogy and enable them to collaborate or share ideas relating to EE even beyond the mere compilation of an e-portfolio (Eynon, Gambino, \& Torok, 2014). This is facilitated by communicating through technology. Habron (2015) highlights the significance of applied learning and skills needed in EE and explores how e-portfolios enable students to provide a range of evidence to demonstrate their EE learning. In this era, collaboration is facilitated by the use of technology. This means that activities that form part of an e-portfolio should be designed to encourage the desired interaction between the students both to enhance learning and develop collaborative skills.

The implementation of an e-portfolio showed both successes and challenges as outlined below.

\section{Successes}

Smolyaninova and Shilin's (2011) findings showed that an e-portfolio could introduce IT into the courses which had no close connection with IT. Furthermore, it enabled the students to upload online learning materials and develop TPCK which is important for future teachers. Considering Smolyaninova and Shilin's (2011) findings, e-portfolios address the need for a new assessment strategy in a transformed education environment. This suggests that employing e-portfolios may yield better results for a university that has a transformed education environment. Belgard (2013) and Garrett (2011) state that employing e-portfolios in teacher education programmes demonstrates improvement like an increase in pedagogical and technical content knowledge. Furthermore, Belgard (2013) posits that students develop collaborative skills when compiling and sharing evidence in the e-portfolio. Van Wyk (2017) states that an e-portfolio affords pre-service students the opportunity to use various types of social media tools and other ICT tools such as podcasts, blogs, PowerPoint presentations, e-discussion forums and WhatsApp groups for subject-related issues. Strydom and Barnard (2017) concur with Van Wyk (2017) that an e-portfolio provides pre-service students an opportunity to explore ICT and other relevant Web 2.0 technologies (social media tools, referring to Facebook and WhatsApp groups). The engagement of students with these technologies by means of an e-portfolio improves pre-service students' technological competencies and enhances their digital pedagogy which is required in the modern classroom environment.

Smolyaninova and Shilina (2011) found that an e-portfolio was successfully employed in the academic processes at the Institute of Education, Psychology and Sociology, Siberian Federal University (SFU) to align educational standards and competencies. This occurred because the system of higher education in Russia was being updated, and the transition warranted the development of a new assessment tool. According to Smolyaninova and Shilina (2011), Web 2.0 technology users had the opportunity to manage the content of the information system considering what they liked and disliked. Furthermore, the users had an opportunity to upload files, which included photographs and shared opinions and ideas, using Facebook as a social network.

The findings of Smolyaninova and Shilin's (2011) reveal that implementing an e-portfolio is a beneficial assessment strategy for universities, with the use of e-portfolios growing exponentially within a period of one year over a range of subjects, which enhanced the IT competency of faculty members as well as students. E-portfolios motivated the SFU administration to develop a universitywide e-learning strategy. Erasmus and Joubert (2017) maintain that one important advantage of e-learning is that "it bridges the gap between a lecturer and a student in different geographical locations so that students can learn anytime and anywhere" (p. 1013). E-portfolios are increasingly being used for the assessment of such learning Carl and Strydom (2017) state that "In the South African context, 
e-portfolios are increasingly being considered in teacher training programmes, to enable student teachers to reflect in, on and about practice in a structured way, whereby they demonstrate their growth and development as professionals" (p. 1). A key point here is that assessment has moved away from solely assessing knowledge, and now includes the assessment of other "skills and attributes" such as "acquisition, integration and application of different types of knowledge" (p. 2), and collaboration.

\section{Challenges}

Smolyaninova and Shilina (2011) highlight the risks of using an e-portfolio in the educational university environment, pointing to low ICT competency levels in higher educational institutions of Russia as a challenge. Ololube, Ubogu and Egbezor (2007) state that a similar situation exists in Nigeria, while Erasmus and Joubert (2017) found that low ICT literacy is a problem in South African ODeL higher education institutions. Carl and Strydom (2017) state that "the level of digital skills of students can neither be assumed nor ignored" (p. 8). Other challenges included the difficulties in mastering the use of the software (Bhattacharya \& Hartnett, 2007). According to a study by Strydom and Barnard (2017), even the millennial students were not au fait with the required technologies and the level of utilisation was not as good as expected. Most of the pre-service students requested for hands-on training in terms of multimedia skills such as adding images, videos and sound clips and granting access to their respective portfolios when the project began. Carl and Strydom (2017) caution that "although it is important to provide students with the necessary technical skills, special care should be taken to prevent technologies from dominating their time and attention, but rather that the learning processes ought to be carefully explained and scaffolded" (p. 6). Having discussed the academic perspectives on the use of an e-portfolio as an assessment strategy, methodology issues are addressed in the next section.

\section{METHODOLOGY}

The methodology section starts by addressing the research paradigm and design. This study aimed to explore how an e-portfolio that is used as an alternative method of assessment enhances pre-service teachers' digital pedagogy in an EE module. Qualitative research was used to elicit information from students by allowing them to share their lived experiences of compiling an e-portfolio and to explore whether their digital pedagogy was enhanced (McMillan \& Schumacher, 2010). In addition, the perspective of the researcher as an insider provided a deeper understanding of the students' lived experiences of compiling an e-portfolio in an EE honours module (Babbie \& Mouton, 2012). Furthermore, a qualitative, phenomenological approach was used to determine how data would be collected, analysed and interpreted with the intention of producing trustworthy results as recommended by Rubin and Babbie (2013).

Purposive sampling was used to choose a sample of students who had registered for the WSDEE module. The sample was comprised of 13 participants. Semi-structured interviews were used to generate data because they allowed probing as the students were perceived to have rich information about the implementation of e-portfolios for summative assessment. Interviews were conducted telephonically after making appointments with students. To avoid the limitations of postal delivery that takes a long time (Dakwa, 2015), telephonic interviews were arranged since the study was conducted in an ODeL environment in which the students were geographically scattered. Purposive sampling enhanced the credibility of the findings in terms of how the use of an e-portfolio for assessment improved future teachers' technological pedagogy (Palys, 2008). Document analysis was also done by reviewing the e-portfolios of these students.

Ethical principles were observed because ethical clearance was sought and obtained by the project leader prior to the commencement of this study, while consent was also sought from the participants as recommended by Marshall and Rossman (2011). Principles such as privacy, confidentiality, anonymity and informed consent were observed (Marshall \& Rossman, 2011). 
Analysis of data was done thematically, revealing three themes that were embedded in the data (Feza, 2015; Rubin \& Babbie, 2013). Analysis of interview data was continuous, being done after each interview session. Data were transcribed and processed, and key words were identified, coded and clustered into categories. The perusal and analysis of the students' portfolios was done to support the interview data. Overarching themes emerged, namely: the significance of an e-portfolio, technological competencies of preservice students, and the development of collaborative skills.

The main limitation of the study was geographical distance because the study was conducted in an ODeL context which prevented face-to-face interviews and effective probing. One student's call dropped in the middle of the interview and efforts to talk to the student again were in vain. Two students' phones were off despite many attempts made to call while one student's phone rang but was not answered. However, the information gathered from the 9 students who participated was adequate to answer the research questions. The findings are presented in the next section.

\section{DISCUSSION OF THE FINDINGS}

Triangulated data from literature, documents and interviews led to the determination of three themes, namely, the significance of assessing EE by means of an e-portfolio; improvement in pre-service teachers' technological competency; and the development of collaborative skills.

The study purposed to answer three research questions.

RQ1: What is the significance of an e-portfolio as an alternative way of assessment in EE?

Findings revealed that an e-portfolio was a useful alternative method of assessment. The portfolio was based on a specific topic in EE, namely, waste management through recycling compared to the traditional way of burning waste. The issue of recycling featured when students were answering the questions on an activity on the Eco-Schools programme ${ }^{1}$. An e-portfolio activity on Eco-Schools exposed them to recycling activities because they were required to visit recycling plants to observe the recycling processes which is an environmental strategy to manage waste, and to digitally record their observations, for example, by means of photographs.

In addition, the e-portfolio was used to evaluate the effectiveness of the WSDEE module (Bates, 2010). The process of compiling an e-portfolio enhanced pre-service students' technological pedagogy, particularly electronic assessment on EE (Maher \& Gerbic, 2009). One interviewee had this to say about the significance of an e-portfolio as an assessment tool:

An e-portfolio was important because some of us did not know anything about this kind of assessment. Now I know how to do electronic assessment.

Therefore, according to the participant, an e-portfolio was important because it improved the student's knowledge of environmental sustainability on matters such as managing waste through recycling. The success of using an e-portfolio in assessing the module in question supports Maher and Gerbic's (2009) study that showed that students employed an e-portfolio as an assessment tool to create a cross-curricular unit of study on the topic 'Education for Sustainability' for primary school children which could include video clips, sound clips and images. Maher and Gerbic (2009) state that the e-portfolio assessment is also authentic, one of the key principles of the National Qualifications Framework (South African Qualifications Authority, 2000) which addresses practical competence, namely, "the demonstrated ability, in an authentic context, to consider a range of possibilities for action, make considered decisions about which to follow and to perform the chosen action" (p. 17). 
RQ2: How does the use of an e-portfolio as an alternative method of assessment enhance EE preservice teachers' digital pedagogy?

The data from the interviews and document analysis confirmed that an e-portfolio exposes student-teachers to various technologies that could be used in teaching and learning in the digital classroom. This finding supports Van Wyk (2017) who found that an e-portfolio could empower prospective teachers to integrate technology into teaching and learning.

The document analysis revealed photographs that were taken by participants during their visits to the recycling plants which served as evidence for their e-portfolios as this was part of the e-portfolio requirements. After the visits, the pre-service students downloaded the photographs, adjusted them, imbedded and integrated them into an e-portfolio text. The information was also prepared as PowerPoint slides which could be used to teach learners. In this way, the e-portfolio enhanced preservice teachers' technological pedagogy, agreeing with Maor (2017) who states that e-portfolios may enhance the students' learning experience. When interviewed an interviewee said:

After taking photos from the recycling plant, I learned to download and adjust photographs and even attach them in the portfolio. This will help me to effectively teach solutions to waste.

However, another interviewee said:

I needed to have somebody to show me how to adjust the photographs.

A common view amongst the interviewees was that an e-portfolio afforded them an opportunity to have online assessment that they had not been exposed to before, such as submitting their work via an e-portfolio site. When interviewed, one interviewee said:

An e-portfolio was a good exposure to do things electronically. It was completely new for me to do electronic work. I learnt to prepare a PowerPoint presentation to answer one of the e-portfolio activities and then e-filing to submit an e-portfolio. I also used the internet to search for information. This is one of outstanding things because I became aware that, in other countries, Eco-Schools are progressing more than in South Africa. My greatest challenge was connectivity because I live in a rural area.

It is evident that using an e-portfolio improved pre-service students' technological pedagogy relevant to digital teaching and learning of EE. However, the teachers in rural areas may find it difficult to practise what they learned due to a lack of internet connectivity.

In addition, the pre-service teachers used WhatsApp to share e-portfolio evidence. This concurs with Van Wyk's (2017) evidence that students formed a WhatsApp group to share subject-related issues, thereby developing a community of practice. The interviewees indicated that they would use WhatsApp to communicate information to the learners and parents regarding natural hazards such as floods, cyclones and current events like environmental conferences to keep them updated on environmental issues.

The analysis of documentation was based on the e-portfolios submitted by pre-service teachers. Evidence of activities was mostly photographic. Furthermore, data revealed two scenarios in terms of the submitted e-portfolios. The first scenario was that photographs were embedded in the e-portfolio text and were given captions and aligned to specific sections. The photographs were supported with textual explanations. In this scenario, the students explained what was happening and showed that they were involved.

The second scenario was that the textual discussions were provided without reference to the evidence which also consisted of photographs. The photographs were attached at the end of text 
largely copied from the internet without reference to such appendixes. This showed that the work was not the students' effort, confirming Smolyaninova and Shilina's (2011) opinion that among the risks of using an e-portfolio in the educational university environment is plagiarism. This means that some students did not benefit from an e-portfolio to learn about waste management through the recycling process in the field of EE. This spoiled the good spirit of Mmogo or working together as a community of practice.

Furthermore, not all preservice teachers in EE were adequately prepared in terms of technological pedagogy because some students failed to submit e-portfolios on the e-portfolio site. This supports the findings of Smolyaninova and Shilina (2011) who mention that preservice teachers are not adequately prepared in terms of technological competency, and Strydom and Barnard (2017) who indicated that irrespective of engaging with 'millennial' students during their study, it was evident that the assumption that all the students could use the necessary technologies as envisaged was not always correct. It can thus be concluded that 'millennials' are not necessarily conversant with the technological pedagogy that is required in the digital teaching and learning context.

In sum, various challenges emerged from the use of e-portfolio such as a lack of connectivity, lack of data and lack of guidance to work online while compiling an e-portfolio.

RQ3: How does the use of an e-portfolio as an alternative assessment tool develop collaborative skills?

Findings revealed that an e-portfolio afforded the students an opportunity to collaborate during the compilation of the e-portfolio, mainly on how an e-portfolio should be written and what should be included as evidence. Collaboration is key if students are to become a community sharing information about the kind of knowledge and specific evidence required during the compilation of an e-portfolio (Ally, 2004; Belgard, 2013; Kop \& Hill, 2008; Roos, 2012). This viewpoint is supported by Boulton (2014) who states that an e-portfolio can be used as an alternative method of assessment to showcase collaborative skills. In this study, the students collaborated by sharing photographs as evidence of recycling activities that addressed the issue of sustainability. This was one of the e-portfolio activities, namely, to form a community of practice in their endeavours as they connected and interacted with each other to share information. By using an e-portfolio as an assessment strategy, students were provided with an opportunity to collaborate. The idea is supported by McCormick (2004) who states that employing digital technologies provides opportunities for both "collaborating to learn" and "learning to collaborate" (p. 159), in this case learning about waste management (recycling) and learning to work with others to solve a common problem, a community of practice.

Despite these benefits, collaboration during the compilation of an e-portfolio led to students committing plagiarism, manipulating data and contravening confidentiality when they shared evidence, especially photographs confirming literature as highlighted by Smolyaninova and Shilina (2011). Some of the evidence provided in the e-portfolios such as photographs were simply copied by students, did not have captions and were not referenced in the text. This means students did not learn anything about the issues of waste management through recycling. Essentially, all they learnt was how to cut and paste (Trinchera, 2002). A way of addressing this would be to include an activity on reflection of what transpired throughout the process of compiling an e-portfolio.

\section{CONCLUSION}

This study explored how the use of an e-portfolio as an alternative method of assessment in EE enhanced pre-service teachers' digital pedagogy, by investigating the WSDEE module. Three research questions were answered, namely, RQ1: What was the significance of an e-portfolio as an alternative way of assessment in EE?; RQ2: How does the use of an e-portfolio as another method of assessment enhance pre-service teachers' digital pedagogy?; and RQ3: How does the use of an e-portfolio as an alternative assessment tool develop collaborative skills? The pre-service teachers learned how to 
prepare an e-portfolio and submitting it online to the university. Based on the answers to the research questions, one conclusion is that using an e-portfolio as an assessment strategy in EE can enhance pre-service teachers' digital pedagogy. However, the use of an e-portfolio for assessment showed that some students did not improve their IT skills.

The author recommends that the university implements a support programme for students who struggle with access to and use of IT, and address the problem of connectivity in rural areas by consulting with the students to establish the intensity of the problem and liaising with authorities and internet suppliers like Telkom, and cell phone companies like Vodacom, M-Net and Cell C to have a way forward on how connectivity could be strengthened. The lecturers should include more activities that would improve pre-service teachers' technological pedagogy.

The areas that need further research are identified as follows: (1) a study could be conducted on how best students can be supported in completing an e-portfolio to enhance their digital pedagogy; (2) an investigation is needed regarding which activities can be included in an e-portfolio to promote pre-service teachers' technological pedagogy; (3) a study is needed to determine how an e-portfolio can be used to address technological knowledge in EE; and related to this, (4) there is a need to investigate why some schools are not involved in the Eco-Schools project because schools that are registered with the project assist in enhancing pre-service student-teachers' digital pedagogy.

\section{ACKNOWLEDGMENT}

This study reported on the use of e-portfolio as an alternative assessment strategy in open distance learning, and acknowledges the project leader, Professor M.D. Magano. 


\section{REFERENCES}

Ally, M. (2004). Role and function of theory in online education development and delivery. Retrieved from https://www.calvin.edu/ dsc8/documents/LearningTheory2008-Ally.pdf

Babbie, E., \& Mouton, J. (2012). The practice of social research (13th ed.). Cape Town, South Africa: Oxford University Press.

Bates, A. W. T. (2010). Technology, e-learning and distance education (2nd ed.). London, England: Taylor \& Francis.

Belgard, S. F. (2013). Portfolios and e-portfolios: Student reflection, self-assessment, and goal setting in the learning process. In J. H. McMillan (Ed.), Sage handbook of research on classroom assessment (pp. 331-346). Thousand Oaks, CA: Sage. doi:10.4135/9781452218649.n19

Bhattacharya, M., \& Hartnett, M. (2007, October). E-portfolio assessment in higher education. In Proceedings of the 37th ASEE/IEEE Frontiers in Education Conference (pp. 1-6). IEEE Press.

Binkley, M., Erstad, O., Herman, J., Raizen, S., Ripley, M., Miller-Ricci, M., \& Rumble, M. (2012). Defining twenty-first century skills. In P. Griffin, B. McGaw, \& E. Care (Eds.), Assessment and teaching of 21 st century skills (pp. 17-66). Springer. doi:10.1007/978-94-007-2324-5_2

Boulton, H. (2014). e-Portfolios beyond pre-service teacher education: A new dawn? European Journal of Teacher Education, 37(3), 374-389. doi:10.1080/02619768.2013.870994

Boulton, H., \& Hramiak, A. (2012). E-Flection: The development of reflective communities of learning for trainee teachers through the use of shared online web logs. Reflective Practice, 13(4), 503-515. doi:10.1080/1 4623943.2012.670619

Carl, A., \& Strydom, S. (2017). e-Portfolio as reflection tool during teaching practice: The interplay between contextual and dispositional variables. South African Journal of Education, 37(1), 1-10. doi:10.15700/saje. v37n1a1250

Dakwa, F. (2015). The interview method. In C. Okeke \& M. van Wyk (Eds.), Educational research: An African approach (pp. 296-313). Cape Town, South Africa: Oxford University Press.

Dillenbourg, P. (1999). Introduction: What do you mean by "collaborative learning"? In P. Dillenbourg (Ed.), Collaborative learning: Cognitive and computational approaches (pp. 1-19). Oxford, England: Elsevier.

Downes, S. (2007). Learning networks in practice. In D. Ley (Ed.), Emerging technologies for learning (pp. 19-27)., Retrieved from http://www.mmiweb.org.uk/publications/ict/emerging_tech02.pdf

Dunbar-Hall, P., Rowley, J., Bennett, D., Blom, D., \& Hitchcock, M. (2013, September). ePortfolios in music and creative arts education: Innovating to inspire learning. In Redefining the musical landscape: Inspired learning and innovation in music education - XIX National Conference Proceedings (pp 82-87). Parkville, Victoria: Australian Society for Music Education. http://hdl.handle.net/20.500.11937/55358

Erasmus, B. J., \& Joubert, J. P. R. (2017). Information and communication technology skills in higher education: The case of a distance learning institution. Journal of Contemporary Management, 14(1), 1010-1034.

Eynon, B., Gambino, L. M., \& Torok, J. (2014). Reflection, integration, and ePortfolio pedagogy. Retrieved from http://c21.mcnrc.org/pedagogy/ped-analysis/

Feza, N. (2015). Qualitative data analysis. In C. Okeke \& M. van Wyk (Eds.), Educational research: An African approach (pp. 458-475). Cape Town, South Africa: Oxford University Press.

Garrett, N. (2011). An e-portfolio design supporting ownership, social learning, and ease of use. Journal of Educational Technology \& Society, 14(1), 187-202.

Habron, G. (2015). Integrating eportfolios into sustainability education. International Journal of ePortfolio, $5(2), 123-134$.

Hallam, G., \& Creagh, T. (2010). e-Portfolio use by university students in Australia: A review of the Australian e-Portfolio Project. Higher Education Research \& Development, 29(2), 179-193. doi:10.1080/07294360903510582 
Heinrich, E. (2008). Contrasting approaches: Institutional or individual ownership in ePortfolio systems. In Hello! Where are you in the landscape of educational technology? Proceedings ascilite Melbourne 2008. Academic Press. Retrieved from http://www.ascilite.org.au/conferences/melbourne08/procs/heinrich.pdf

Kop, R., \& Hill, A. (2008). Connectivism: Learning theory of the future or vestige of the past? International Review of Research in Open and Distance Learning, 9(3), 1-13. doi:10.19173/irrodl.v9i3.523

Maher, M., \& Gerbic, P. (2009). E-portfolios as a pedagogical device in primary teacher education: The AUT University experience. Australian Journal of Teacher Education, 34(5), 4. doi:10.14221/ajte.2009v34n5.4

Maor, D. (2017). Using TPACK to develop digital pedagogues: A higher education experience. Journal of Computers in Education, 4(1), 71-86. doi:10.1007/s40692-016-0055-4

Marshall, C., \& Rossman, G. B. (2011). Designing qualitative research (4th ed.). Los Angeles, CA: Sage.

McCormick, R. (2004). Collaboration: The challenge of ICT. International Journal of Technology and Design Education, 14(2), 159-176. doi:10.1023/B:ITDE.0000026495.10503.95

McMillan, J. H., \& Schumacher, S. (2010). Research in education. A conceptual introduction (4th ed.). New York, NY: Harper Collins College.

Mimirinis, M. (2018). Qualitative differences in academics' conceptions of e-assessment. Assessment \& Evaluation in Higher Education, 44(2), 233-248. doi:10.1080/02602938.2018.1493087

Ministry of Education, Government of New Zealand. (2007). The New Zealand curriculum. Wellington, New Zealand: Learning Media.

Morze, N., \& Buinytska, O. (2015). Open e-environment - The key instrument of the education quality. International Journal of Research in E-learning, 1(1), 27-46.

Odeke, G. J. E. (2012, April). Enhancing sustainability in higher education through a global universities partnerships: Perspectives from UNEP's environmental education and training. Paper presented at the Best of Both Worlds International Conference. Academic Press.

Okaz, A. A. (2014). Integrating blended learning in higher education. Procedia: Social and Behavioral Sciences, 186, 600-603. doi:10.1016/j.sbspro.2015.04.086

Ololube, N. P., Ubogu, A. E., \& Egbezor, D. E. (2007). ICT and distance education programs in a sub-Saharan African country: A theoretical perspective. Journal of Information Technology Impact, 7(3), 181-194.

Roos, V. (2012). The mmogo-method: An exploration of experiences through visual projections. Qualitative Research in Psychology, 9(3), 249-261. doi:10.1080/14780887.2010.500356

Siemens, G. (2005). Connectivism: A learning theory for the digital age. Retrieved from http://er.dut.ac.za/ bitstream/handle/123456789/69/Siemens_2005_Connectivism_A_learning_theory_for_the_digital_age.pdf

Smolyaninova, O. G., \& Shilina, N. G. (2017, June). e-Portfolio in higher educational institutions of Russia. In Proceedings of the ITI 2011 33rd International Conference on Information Technology Interfaces. Academic Press.

South African Qualifications Authority. (2000). The national qualifications framework and quality assurance. Retrieved from http://www.saqa.org.za/docs/pol/2003/quality_assure.pdf

Strydom, S., \& Barnard, M. (2017). A tale of two faculties: Exploring student experiences of e-portfolio implementation as a vehicle of reflective learning at Stellenbosch University. The Independent Journal of Teaching and Learning, 12(2), 78-91. doi:10.20853/31-3-834

Trinchera, T. (2002). Cut and paste plagiarism: What it is and what to do about it. Community \& Junior College Libraries, 10(3), 5-9. doi:10.1300/J107v10n03_02

Van Wyk, M. M. (2017). An e-portfolio as empowering tool to enhance students' self-directed learning in a teacher education course: A case of a South African university. South African Journal of Higher Education, 31(3), 274-291. doi:10.20853/31-3-834

Wildlife and Environment Society of South Africa. (2019). WESSA eco-schools. Retrieved from http://wessa. org.za/wessa-eco-schools/ 


\section{ENDNOTES}

The Eco-Schools programme is an international programme of the Foundation for Environmental Education (FEE) that was developed to support environmental learning in the classroom. The programme was implemented in South Africa in 2003 by The Wildlife and Environment Society of South Africa (WESSA, 2019).

Matlala Violet Makokotlela is a lecturer at the University of South Africa (UNISA) in the Department of Science and Technology Education. Her work experience includes lecturing at a university and a College of Education. She holds a PhD in Environmental Education from UNISA. Dr Makokotlela's research interests is in curriculum, sustainability, climate change, open education resource, and open distance learning. She was involved in conference organisation. Dr Makokotlela presented papers at local and international conferences, reviewed conference abstracts, papers and articles, and also reviewed book chapters. 